\title{
Graves, R. \& Hyland, T. (Eds.). (2017). Writing assignments across university disciplines. Bloomington, IN: Trafford.
}

\section{Daniel P. Richards \\ Old Dominion University}

For the last three years, I have been part of a team of multi-disciplinary faculty that holds a weeklong workshop each semester for approximately twenty teachers. These teachers, migrating to our cozy space in the library from all corners of campus, have applied-they get paid a modest sum, which is not nothing - to attend our workshop in the hopes of improving their ability to integrate writing assignments into their courses. The workshops are part of a larger initiative, Improving Disciplinary Writing, which was borne out of a needs assessment from our regional assessment body. It is designed to bring together faculty, through workshops and grants, to think collectively about how writing gets taught and ought to be taught differently across and within disciplines. And what we see time and time again is that although each group of twenty teachers is new each semester, and although the ranks consistently vary from adjunct (sessional) to full professor, and although some work in musty chemistry buildings and some in obscure art buildings and some in sleek see-through engineering buildings, the disembodied echoes of frustrations and complaints and discovery and hope and solace from groups past get re-vocalized by groups present. As facilitators, we are not flustered by this fact; rather, we find our own solace in the connection and camaraderie through shared experience happening across disciplines and spaces on campus.

However romantic this kinship, our work does not and cannot stop there. Our teacher participants, mostly from STEM and social sciences, consistently clamor for more research-based approaches, more examples of how writing gets inserted into courses without compromising "content," yes, but also programmatic visions they can take back to their department chairs. Anecdotes and auto-ethnographies from composition teachers only go so far. By the end of the workshop, participants become cognizant of the interconnected writing lives of students. They move (mostly) away from the mindset that students struggle with writing because Comp 101 does not do its job properly to a mindset that everyone across campus is responsible for the writing lives of 
Volume 27, 2017

http://journals.sfu.ca/cjsdw

students, indeed that the variegated student trajectories in a world of ever-increasing dual enrollments and transfer credits and changes of major behoove a pedagogical approach steeped in localized student experiences and emerging out of the needs of individual programs. The exigence emerging out of this realization is the need for practical, accessible scholarship that provides models for how to analyze how students develop—or don't-as writers in their own programs. Roger Graves and Theresa Hyland's Writing Assignments Across University Disciplines responds to this exigence perfectly.

As is expected, Graves and Hyland-both respected researchers in their own right-continue to paint a more refined picture of writing programs and curricula across Canada. This collection builds off their collaborative work (along with Boba Samuels) published in Written Communication in 2010, “Undergraduate Writing Assignments: An Analysis of Syllabi at One Canadian College." I suggest readers at least review that article before sitting down with Writing Assignments Across University Disciplines, mainly because the latter builds directly off the former. The findings from the Written Communication article, while perhaps not entirely surprising, were significant for both their unmasking of Canadian writing curricula on a minute level and their modeling of institutional research for the purpose of programmatic and institutional understanding and, hopefully, revision.

Now, with this recent collection, Graves and Hyland are given the chance to share their expanding vision of this research. As they note in their introduction, they connect the 2010 article and this collection as such: "That investigation [in Written Communication] proved fruitful in many ways and lead directly to the work reported in this book. We wanted to know if what we had found in this one small, liberal arts college would be similar to departments at larger, more research-based universities" (p. x). What they gleaned at Huron University College, while useful for that (Hyland and Samuels') institution, was limited. They wanted more: "We also wanted to know if we could replicate the results from one smaller institution at other small institutions. Did the wide range of assignments we found also occur within other academic units or was it the product of a liberal arts context?" (p. $\mathrm{x}$, emphasis added). And while I question the appropriateness of the word "replicate" as used in this context, as it seems to indicate more of an expansion than a replication of results for the purposes of reliability, the spirit of building is there: keep conducting program profiles (see Anson \& Dannels, 2009) across the nation to identify patterns across and within disciplines in terms of genre, quantity, and student experience. By and large, most chapters in this collection-save for the last two, which focus on the faculty point of view-map out the writing requirements of a distinct curricular program or unit in an effort to do this building work. 
Volume 27, 2017

http://journals.sfu.ca/cjsdw

Before delving into summary, I'd like to clarify something that Roger Graves himself sets the stage for in the first line of the first chapter when he asks the loaded question: "What do we know about what students write in their undergraduate programs of study?" (p. 1). The question is loaded not because it is bursting through an unpunctured wall of research but because this is not a universal question. Readers in Canada or the United States, for example, will have different responses, as will readers at small or large universities, public or private ones, and as will readers holding WPA positions and those who do not. Depending on you, the reader, and your own positionality and administrative experience, the answer could be anywhere from "not much" to "well, quite a bit, actually." Thus, while not explicitly framed as a collection on only Canadian writing studies, I am going to qualify that in light of Graves' question, and the fact that all case studies in each chapter study Canadian institutions, I read this book as being framed early on for a readership of teachers and scholars at Canadian institutions, despite its lack of indication in the title. Quite frankly, "we" — coded as scholars at Canadian universities (note, I'm not one of them)-know relatively little about what "our" students write in "their" programs of study. Graves' question, then, is an imperative one for Canadian writing studies to ask and is thus doing critical work in that area, even if it doesn't seem to be blazing new paths in programmatic research on a more global, or even American, scale.

What Graves is explicit about in chapter one is the research to which he is responding: Chris M. Anson and Deanna P. Dannels' (2009) call to create program profiles for each institution—which, in the case of Graves, is the University of Alberta-so as to "map" the curriculum students encounter. Graves takes it upon himself to conduct a large-scale analysis of writing across five different programs at Alberta, a large public university: Community Service Learning, Political Science, Physical Education and Recreation, Pharmacy, and Nursing. His focus is on understanding how writing operates within each program by coding each and every writing assignment (anything over $5 \%$ course weight) across all classes in terms of genre, length, feedback, topic choice, and other relevant features (p. 7). Graves begins the chapter with an overview of assignment genres at the postsecondary level, and then moves into sharing insight into how he developed a coding protocol and guide, outlining specific modification to the coding for each program. The coding guide is shared as an appendix and offers an immediate instrument for researchers to deploy at their own institution, Canadian or not. From there, Graves goes into detail about how the genres were conceived by each program and how they were assessed. He notes that in two programs (pharmacy and physical education and recreation) "over 50 different genre names were given by instructors" (p. 3) while nursing had the most dominant and consistent understanding of genre, using only 13 different names 
Volume 27, 2017

http://journals.sfu.ca/cjsdw

to describe student work ("papers" and "presentations" were coded as most common). Overall, the amount of writing in these five programs is high, and Graves makes the case that students in the arts don't write "more" or "more often" but just craft longer genres. The vast majority of assignments had the professor as the audience, but this was assumed to be the default if no audience was described. Some programs (physical education and recreation) were only giving professor feedback on less than $10 \%$ of student writing, while others (nursing) on more than $95 \%$. Approximately $70 \%$ of writing assignments had no information for students on how the genre was to be assessed, noting mainly that the broader purposes of the writing assignments were predominantly workplace preparation. As a mostly quantitative study, Graves' chapter is limited in direct pedagogical application or in exploration of why these variations exist between disciplines-as he readily admits. In fact, he articulates that the purpose of this study-and this type of study, of which the subsequent five chapters mimic-is to "hold a mirror" back to programs and show them what their faculty are currently practicing, not as an indictment on the teachers but as a useful communicative or consultational tool to guide conversations between faculty and administrators in a specific program unit. The quantification of types of genres, page length, and expectations of assessment, while limited, provides for Graves an easy starting point for more long-term conversations about curriculum redesign in many corners of his campus.

The next five chapters are less institutional in scope than Graves' and instead offer program-level research on a specific academic unit in response to Graves' call for added depth of research for individual universities. The first of these, chapter two, is Marion McKeown's research study of an arts faculty (department) at a small Canadian university, Royal Military College. McKeown begins the chapter with precisely how the data were collected-a common and productive theme throughout the remaining chapters. The aim was to broach specifically how writing assignments helped students learn disciplinary knowledge. As such, McKeown's research focused on directives given to students, with 412 assignments analyzed in all. McKeown draws the significance of her research directly from how it compares to Graves, Hyland, and Samuels' research study from 2010, drawing parallels and differences on a point by point basis (and reinstating the notion of "replication" framing the introduction of the collection). Overall, McKeown found meaningful similarities and differences between her own institution and that from the 2010 study. The similarities were that $53.7 \%$ of assignments used the innocuous genre title of "assignment," "essay," or "paper," and that no course in the arts faculty went without a writing assignment, and very few weighted writing assignments under $10 \%$. The main difference in her study was found in "variation labels" (p. 37) of genre, which 
Volume 27, 2017

http://journals.sfu.ca/cjsdw

included "journal entry," "proposal," and "draft"-all of which were far more present at her institution. The claim made by Graves in the 2010 study that arts departments and programs have longer page lengths and fewer assignments was proven to bear out, as McKeown's research found that students write an average of 123.1 pages per academic year, compared to Graves, Hyland, and Samuels' number of 87 in their original study. This was one of the highlights McKeown extracts from her data. The chapter ends with a relatively in-depth look of how the data facilitated meaningful conversations with the faculty through interviews and presentations. During the presentation and conversations, faculty were interested less in coming to consensus on the names of genres than they were in discussing effective "instructional characteristics" (p. 41), circling back to the objective of the study, which was "to discover how the writing assignments helped the students understand the distinctive features of disciplinary knowledge and develop [...] the broader skills of critical thinking" (p. 41, qtd. in Graves, Hyland, \& Samuels, 2010). This individual chapter doesn't give enough time to consideration of the question of how, but does provide a convincing argument, based on a recounting of how the data was shared and discussed, that interaction with all of those involved-faculty, administrators, and students-is necessary in the development of effective syllabi, as evidenced by how McKeown's own research project was able to mobilize the unit in that direction.

Chapter three, written by Anne Parker at the University of Manitoba, explores the types of papers asked of mechanical engineering undergraduate students and, perhaps more importantly, the rubrics the instructors have developed to assess such writing. Parker builds off of McKeown's research by arguing not only for the joint development of writing assignments but the joint development of rubrics to assess them. Parker is interested in learning more about which and in how many courses mechanical engineering students learn writing, or as the Canadian Engineering Accreditation Board (CEAB) would have it, Attribute 7 (A7: Communication Skills) of the core competencies for engineers. While part of a larger national study on communication skills in engineering, Parker wanted data on how well their specific program at Manitoba was preparing students for communication in the workplace, studying the attempts teachers make to have communication integrated in a way that "mirrors" engineering practice. In addition to collecting assignments and materials, Parker sought feedback from industry and students and built rubrics around them, positioning rubrics, philosophically, as an instrument of assessment of a specific attribute, yes, but also as a tool for communicating with all stakeholders. In this way, rubrics ought to be flexible enough to adapt to specific programs while stable enough to meet the needs outlined by the accreditation bodies. Parker provides a good amount of detail of how she developed common language amongst stakeholders and 
Volume 27, 2017

http://journals.sfu.ca/cjsdw

provides an example of a rubric co-developed between academics and industry. The importance of this rubric is highlighted by her findings that most writing assignments in mechanical engineering provide very vague genre definitions ("assignment," "project") and provide little in the way of length expectations and audience. In combining these findings with her positive experience in co-developing rubrics, Parker argues that there is a distinct need in mechanical engineering to clarify assignment guidelines and create more meaningful, situated contexts for communicating. This is a smaller part of her larger argument that this type of clarity can take place through joint rubric design. Also of note is that this chapter will be of interest to teachers of technical communication, as it speaks to the importance of having a course of this kind in engineering programs.

Chapter four continues the thread of program profiles, but this time in a life sciences department at a Central Canadian University (CCU) in southern Ontario. The chapter's author, Andrea L. Williams, situates her analysis of syllabi and assignments within the larger conversation and rhetoric, history, and sociology of science. Operating from the standpoint-as convincingly argued by the likes of Charles Bazerman, Alan G. Gross, and Greg Myers—that science writing involves not simply recording of natural facts but an epistemological process of the production, reproduction, and authorization of scientific knowledge, Williams sees syllabi as imbued with the explicit and implicit values, beliefs, and expectations of a given scientific community. Analyzing such documents, therefore, can unmask and then foreground the relationships scholars and practitioners often take for granted much in the same way Bazerman argues that "words arise out of the activity, procedures, and relationships within the community" (p. 74, qtd. in Bazerman, 1988). After giving a thorough and resourceful background on the various perspectives of writing in the life sciences, Williams delves into the 59 syllabi she and her researchers accumulated, deploying roughly the same methodology as the previous chapters: analyzing each assignment (in this case, 195) and coding for frequency, genre, and instructional characteristics. Williams and researchers found a familiar pattern: students in the department of life sciences write frequently, and the number of assignments varies more by course type (e.g., seminar) than by year in the program. Learning goals and methods of assessment were lacking in most courses, but students in life sciences did do a fair amount of scaffolding in their assignments (63\%). That said, Williams does conclude that the life sciences at her institution-and perhaps at others as wellwould do well to further clarify audience for each assignment (as writing for various audiences is an objective) and use more specific labeling with genres, since life sciences can be a challenging discipline to define for students, as it includes several hard sciences. 
Volume 27, 2017

http://journals.sfu.ca/cjsdw

Chapter five, written by Judi Jewinski and Andrew Trivett, breaks a bit from the mold of the previous chapters in a rather productive way by highlighting how a program in mechanical engineering applied the findings of an "environmental scan"-or program profile-of their curriculum. As was expected, their scan of the curriculum found that while the students in mechanical engineering were writing a considerable amount-over 75 writing assignments throughout the program - there was little in the way of direct instruction on writing and revising strategies and in the way of writing-based interaction with peers. The initiative sought to address both of these lacks by rethinking rather substantively the way writing gets taught in their first-year course, ME100: Introduction to Mechanical Engineering, which seeks to have students model the professional written and visual discourse of the industry. By incorporating into the course in-class writing activities, revision requirements, web posting, employment materials (e.g., résumé) assignments, and collaborative design projects, the group at Waterloo was able to accomplish their goal of better preparing students for the professional discourse proficiency required of engineers and also see statistically-significant increases in hiring rates and student satisfaction. Readers tasked with the challenge of integrating writing into an engineering course without sacrificing "content" will find this detailed case study particularly fruitful.

Chapter six marks the end of the program profile chapters with a bang: the authors of this pieceDavid Slomp, Robin Bright, Sharon Pelech, and Marlo Steed of the University of Lethbridge-share how they used the exigence provided by Graves to not only assess the status of writing assignments in their Bachelor of Education curriculum but how they used the exigence to take stock of all assignments in the entire teacher education curriculum and to reimagine completely the program as a whole. A tall task, to be sure, this lengthy chapter details first how the results of their original genre analysis (showing a relatively even mix of 77 different genres across the program, but with substantial workload imbalance) motivated them to conduct a full-scale program redesign, and second how the authors, using a specific theoretical framework, went about implementing the redesign. Readers are given substantive depth about the context of Lethbridge's teacher education program, which accepts 236 students each fall, but more importantly are given a well-researched overview of the various theoretical frameworks of teacher education and how these frameworks are often, and implicitly so, deeply embedded in existing curricular structures. As the team worked toward redesign, the main tension was that of the various configurations between theory and practice, namely between the "technical rational perspective that focuses on a theory-into-practice model [and] the practice-and-theory perspective that is grounded in reflective practice" (p. 151). 
Volume 27, 2017

http://journals.sfu.ca/cjsdw

Overcoming these tensions meant paying attention to the shifting nature of the K-12 systems in the province of Alberta, and more broadly: "Our...redesign work occurred as a shift in education is happening across Canada and the western world as we move from an understanding of learning from a rational/cognitive focus towards recognizing learning as a creative, emergent process" (p. 152). While teacher preparation can be seen as having a more inextricable link to the shifting sands of education, teachers and scholars from all disciplines will most likely find how the authors make direct links to genre analysis, program redesign, and social trends useful.

The final two chapters are paired together in their focus on exploring, from a faculty perspective, the nature of a writing-in-the-disciplines approach to writing theory and the overall value of such research moving forward. Chapter seven, co-authored by Hyland, Allan MacDougall, and Grace Howell, offers a remedy to any readers who up until this point have longed for a more nuanced vision of genre than the one offered thus far in the Course Syllabi Project. Counting the types and quantity of genres can be a useful starting point for administrators "upstairs" but, as the authors share, might paint an oversimplified portrait of what actually happens "downstairs" in the classroom, in office hours, in undocumented conversation. To respond to this criticism and limitation, Hyland, MacDougall, and Howell share the results of a research study—conducted in the Faculty "Attic," well above the classrooms below-in which they conducted focus groups with faculty to glean more indepth information about their own goals in giving students writing assignments (and to get them to think more reflectively about their genre-based decisions in writing instruction). The resulting interviews gave the researchers much more to work with and analyze than did a mere quantitative scan of genre types: participants provided apt metaphors for their conceptions of writing, detailed descriptions of how writing relates to the nature of knowledge in their field, and more refined characteristics of what writing ought to look like in a given discipline, ultimately generating a clearer conveyance of faculty expectations. But the question for them still remains: how much of these differences are chalked up to disciplinary allegiance versus differences in personal preference and dispositions?

In chapter eight, Hyland ends the collection not by answering this question-that, she and her coauthors argue, is for another time and place-but in thinking broadly about faculty receptivity to the type of writing research conducted in the project as a whole. The chapter, aptly titled "Cross-Talk and Crossed Boundaries: Resistance and Engagement when Faculty and Writing Researchers Converse," broaches the daunting question: What now? Hyland frames her chapter in a very relatable way: 
Volume 27, 2017

http://journals.sfu.ca/cjsdw

I'm sure that many of us have had the experience of conducting research on writing, presenting these findings to faculty at our institutions, and then finding that the information has no impact whatsoever. Sometimes, it is almost as if we have said nothing at all. Yet, at other times, the same information delivered in a slightly different format, or for a slightly more receptive audience, seems to create a great stir. Why does this happen? What are the factors that are at play when faculty and writing researchers converse? (p. 210, emphasis added) Building off the seminal work of Segal, Paré, Brent, and Vipond (1998) and their thinking on faculty receptivity of writing research, Hyland interestingly-and productively-incorporates Stern's (2000) values-beliefs-norms (VBN) construct and Gifford's (2008) theory of dilemma awareness and cooperation to posit that "faculty will accept and act upon research findings that they view as credible, useful and important" (p. 211, emphasis added). Hyland draws from interviews with faculty reacting to three studies done at her own institution and thoughtfully and honestly reflects on ways to better approach the delivery of research results (especially when coming from a space as contested and differently-viewed as the writing centre). Specifically, the chapter highlights (a) the challenge of negotiating the perception of "top-down" administration-focused research, (b) the importance of discussing the research results in safe, collegial environments, and (c) the effectiveness of shifting from an "impact-oriented," more heavy-handed approach to the presentation of data to a softer "intent-oriented" approach, where faculty could more clearly glean opportunities for self-driven improvement offered by the data. In all the chapter offers an appropriate bookend to readers seeking ways forward in mobilizing their research to campus stakeholders in rhetorically-savvy, and disciplinary-sensitive, ways. Writing researchers interested in data-driven, practical strategies for "translating" their research and results into this reception-based framework will gain much from reading this final chapter.

As a whole, the value of this collection extends beyond painting a more refined portrait of Canadian writing studies. While it does do so, and well, it has applications at institutions of all types in the United States as well, including two-year colleges, private liberal arts schools, HBCUs, community colleges, and four-year public research institutions. I could very much see this book being including in a graduate level research methods course in writing studies or in a WPA course. The clear outlining of methods, the generous sharing of instruments, and relative use of plainer language positions this collection as a highly-accessible, broadly applicable resource. The limitation of this collection is its lack of situatedness in WAC/WID scholarship as a whole. Yes, the motive of this collection is to take stock of writing curricula across institutions, and this is very localized work to be 
Volume 27, 2017

http://journals.sfu.ca/cjsdw

sure, but Graves and Hyland could have spent more time in the introduction outlining specifically what this collection does for the field, what needles it moves, what body it expands beyond just adding on a layer of Canadian context. There were several points through the collection, but specifically in chapter one, where I would have found it productive to see how this research speaks to or against other large-scale studies, such as Christopher Thaiss and Terry Myers Zawacki's (2006) research on the development of disciplinary identity. Without this contextualization, readers outside the field don't sense alienation, which can be good, but readers within the field will have to do their own leg-work to see how it fits.

In the book's afterword, Heather Graves honestly assesses the value of the book in what I think are two distinct but not disconnected ways. First, Graves identifies the value of the book to readers in writing studies quite cogently: "This collection of essays and the research project that produced them are unique because they offer insight into the nature and scope of writing assignments required of undergraduate students at post-secondary institutions across Canada, information that has not been available previously" (p. 233). This assessment, from what I can see, is correct, but should also not detract readers located in the United States from reading a book that is chock full of well-defined, precise instruments and methods waiting to be deployed and that don't have to pass through customs. And second, although she doesn't frame it as such, Graves provides a reason for the value of the book to readers outside writing studies:

When the findings of discourse analysis and genre research are coupled with conclusions from studies by WID and WAC researchers, as well as scholars in the rhetoric of science/inquiry, it becomes clear that writing is not an add-on, undertaken once the researcher has completed his/her empirical study. Instead writing is integral to knowing in a discipline; knowing is at the heart of disciplinary discourse. (p. 237)

If readers are in need to a book that communicates this notion simply and straightforwardly-and with data-to those outside the humanities, then I strongly suggest you acquire a few copies of the book and disseminate at your own WAC/WID workshop or place one in a receptive colleague's mailbox.

I began this review with an anecdote of my own experience with a WAC/WID initiative on campus. I did so because I read Graves and Hyland collection as being an invaluable resource for those facing similar challenges as we are down at our mid-sized public university in southeast Virginia. We have (relative) institutional buy-in, a modest pot of financial resources, but most likely, and to no one's surprise, have neither forever. It has been a productive initiative so far, with thousands of students 
Volume 27, 2017

http://journals.sfu.ca/cjsdw

reached by way of revised curricula of over two hundred teachers, but many of us worry about the sustainability of such an initiative. More than just providing tips and tricks and strategies for the teaching of writing, how can we train bodies of interdisciplinary faculty to conduct their own research, get to know their own students once the lights of the workshop room are turned off, the English faculty leave, and the echoes cease reverberating? If you are kindred in these concerns and face similar institutional realities, on either side of the 49 ${ }^{\text {th }}$, then I highly suggest purchasing a copyor twelve-of this collection and get faculty in other departments to do so as well. Readers of this book should be excited to find an accessible framework upon which to build their own institutional research, including but not limited to program profiles. Ultimately, the book will be invaluable to those in situations like mine: leading or administering writing in the disciplines programs that are emerging, trying to build from the ground, up.

\section{References}

Anson, C. M., \& Dannels, D. P. (2009). Profiling programs: Formative uses of departmental consultations in the assessment of communication across the curriculum. Across the Disciplines, 6. Retrieved from wac.colostate.edu/atd/assessment/anson dannels.cfm

Bazerman, C. (1988). Shaping written knowledge: The genre and activity of the experimental article in science. Madison: University of Wisconsin Press.

Graves, R, Hyland, T., \& Samuels, B. M. (2010). Undergraduate writing assignments: An analysis of syllabi at one Canadian college. Written Communication 27(3).

Thaiss, C., \& Zawacki, T. M. (2006). Engaged writers and dynamic disciplines: Research on the academic writing life. Portsmouth: Boynton/Cook. 